Part of Journal of Research of the National Bureau of Standards, Volume 15, July 1935

\title{
USE OF 8-HYDROXYQUINOLINE IN DETERMINATIONS OF ALUMINUM, BERYLLIUM, AND MAGNESIUM
}

\author{
By Howard B. Knowles
}

\section{ABSTRACT}

The methods commonly used for precipitating aluminum by 8-hydroxyquinoline from an acetic-acid solution, buffered with ammonium acetate, do not sufficiently define the conditions requisite for complete precipitation. The present article describes a method in which aluminum is precipitated as the oxyquinolate from a solution which has been partially neutralized with ammonium hydroxide, using bromcresol purple as an indicator. Results obtained in the separation of aluminum from beryllium and magnesium, and in the separation of beryllium in the presence of aluminum, iron, titanium, and zirconium, by the described procedure, are given.

\section{CONTENTS}

Page

I. Introduction

II. General considerations _.

III. Experimental work

1. Determination of aluminum 89

2. Determination of aluminum oxide in feldspar

3. Separation and determination of beryllium and aluminum $\ldots . . .91$

(a) Determination of aluminum in the presence of beryllium - 92

(b) Determination of beryllium in the presence of aluminum, iron, titanium, and zirconium

4. Determination of aluminum in the presence of magnesium _._ 93

IV. Recommended procedures

1. Procedure A (for use in presence of beryllium)

2. Procedure B (for use in absence of beryllium)

\section{INTRODUCTION}

A study of the numerous procedures which have been recommended for the determination of aluminum and its separation from other elements by precipitating with 8-hydroxyquinoline reveals that, while conditions governing the precipitation from alkaline solutions have been satisfactorily established, those in which precipitation is effected from acid solutions have not been sufficiently defined. Procedures which recommend that precipitation be made from "faintly acid" or from "neutralized or weakly acid solution" are unsatisfactory, both because of the uncertainty in duplicating conditions for precipitation and the possibility of various interpretations by different analysts. 
The recent investigations by H. R. Fleck and A. M. Ward ${ }^{1}$ and by $\mathrm{H}$. Goto ${ }^{2}$ have defined the limits within which certain elements are precipitated by 8-hydroxyquinoline. Experiments made by the latter show that aluminum is precipitated quantitatively between the $\mathrm{pH}$ values of 4.2 and 9.8 . If aluminum is to be quantitatively separated as the oxyquinolate from an acid solution it is necessary therefore that precipitation be effected in a solution whose $\mathrm{pH}$ value is never less than 4.2 nor in excess of 7.0.

In the method to be described, aluminum is precipitated as the oxyquinolate from an acetic-acid solution, buffered with ammonium acetate, which has been neutralized with ammonium hydroxide to a $\mathrm{pH}$ of approximately 6.8 , using bromcresol purple as an indicator. The aluminum oxyquinolate can be dried and weighed in that form, or it can be dissolved in hydrochloric acid and the solution thus obtained titrated with a standard solution of potassium bromate.

\section{GENERAL CONSIDERATIONS}

In any discussion of the use of 8-hydroxyquinoline as a precipitant, reference must be made to the extensive studies which have been carried out by R. Berg, ${ }^{3}$ F. L. Hahn, and co-workers ${ }^{4}$ and others. ${ }^{5}$ From these it will be found that many elements are precipitated under essentially the same conditions and that direct separations are not always possible. The value of 8 -hydroxyquinoline as a reagent in quantitative analytical chemistry lies principally, although not entirely, in its use after preliminary separations have removed interfering elements. Such separations may include precipitation with ammonium hydroxide, which serves to remove moderate amounts of elements such as magnesium, zinc, manganese, nickel, cobalt, tungsten, and molybdenum; electrolysis with a mercury cathode, which removes elements such as iron, chromium, nickel, cobalt, copper, zinc, tin, and molybdenum; precipitation with cupferron, which precipitates elements such as iron, titanium, zirconium, tin, columbium, tantalum, and others; or the separation of aluminum based on its solubility in sodium hydroxide.

Direct separation of aluminum by precipitating in an acid solution with 8-hydroxyquinoline is accomplished when dealing with solutions containing only aluminum, or aluminum in the presence of beryllium, magnesium, or other elements that are not precipitated in an acid solution, such as lead, the alkaline earth metals, and the alkalies.

The determination of aluminum oxide for the purpose of classifying commercial feldspar presents an almost ideal case in which a precipitation with 8-hydroxyquinoline from an acid solution is most advantageous. In this particular instance, the elements that are precipitated with the aluminum, such as iron, titanium, and zirconium, are generally present in such small quantities that their effect can be disregarded in commercial analyses. If these elements have been determined individually, corrections for their presence can be made.

The determination of beryilium in ores and metallurgical products frequently requires a separation of that element from aluminum,

1 Analyst, 58, 388 (1933).

2 J. Chem. Soc. Japan 54, 725 (1933).

R. Berg. Z. anal. Chem. 70, 341 (1927); 71, 23, 171, 321, 369 (1927); 72, 177 (1927); 76, 191 (1929); 81, 1 (1930).

F. L. Hahn, et al., Z. anal. Chem. 71, 122, 225 (1927).

$\checkmark$ See also Organic Reagents for Metals, p. 41. (Hopkins and Williams, Ltd., London, 1933.) 
with which it is often associated, as well as from certain other elements. For this purpose, precipitation of aluminum from an acid solution by 8-hydroxyquinoline completely separates that element from beryllium, which may then be determined in the filtrate by precipitating with ammonium hydroxide and igniting the precipitate to the oxide. ${ }^{6}$ In such cases, a preliminary precipitation of the aluminum and beryllium with ammonium hydroxide is desirable to separate them from such elements as manganese, calcium, barium, strontium, and magnesium, which would subsequently interfere in the determination of beryllium if the latter is to be precipitated with ammonium hydroxide in the presence of 8-hydroxyquinoline.

In the analysis of alloys, the removal of such common alloying elements as copper, tin, iron, zinc, and nickel by electrolysis with a mercury cathode leaves a solution containing aluminum, and magnesium, if the latter be present. Other elements, such as titanium, zirconium, vanadium, and uranium, which are not removed by electrolysis, must be removed, if present, by other procedures before attempting the precipitation of aluminum. In this, and similar cases requiring a separation of aluminum from magnesium, precipitation from an acid solution by 8-hydroxyquinoline offers a rapid method for the direct separation and determination of aluminum.

\section{EXPERIMENTAL WORK}

Aluminum can be precipitated by 8-hydroxyquinoline from acid solution under two sets of conditions. In the one, as applied to the analysis of feldspar, the addition of a small amount of tartaric acid serves to prevent the formation of precipitates during the partial neutralization with ammonium hydroxide, and the aluminum is precipitated by a rapid addition of the reagent. In the other, with no tartaric acid, the precipitate that is formed by partial neutralization is either dissolved or converted to the oxyquinolate during the slow addition of the reagent. In the latter modification, the ability of 8-hydroxyquinoline to convert an insoluble compound to the oxyquinolate is of interest. R. Berg ${ }^{7}$ states that even the difficultly soluble nickel glyoxime and the copper compound of $\alpha$-benzoinoxime are converted into their respective oxyquinolates by treatment with 8-hydroxyquinoline.

\section{DETERMINATION OF ALUMINUM}

The determination of aluminum by precipitating with 8-hydroxyquinoline, although accomplishing a quantitative separation of that element, yields results that tend to be too high, regardless of whether the precipitate be dried and weighed as the anhydrous aluminum oxyquinolate or whether it be titrated, after solution in hydrochloric acid, with a standard solution of potassium bromate. The results given in table 1 were obtained by precipitating aluminum from an acid solution containing no other elements precipitable by 8-hydroxyquinoline. The aluminum in these precipitates was determined either by drying the precipitate at $140^{\circ} \mathrm{C},{ }^{8}$ by titration of the dried precipitate after solution in hydrochloric acid, or by titration of

\footnotetext{
${ }^{6}$ I. M. Kolthoff and E. B. Sandell, J. Am. Chem. Soc. 50, 1900 (1928). M. Niessner, Z. anal. Chem. 76, 135 (1929).

7 J. prakt. Chem. 115, 182 (1927).

8 The dried aluminum oxyquinolate is moderately hygroscopic and should be weighed without undue exposure to the atmosphere.
} 
solutions of undried precipitates. A study of the results shows that, if amounts of aluminum not exceeding approximately $50 \mathrm{mg}$ are involved, satisfactory determinations can be obtained by weighing the dried aluminum oxyquinolate. If aluminum is to be determined by titration the amount involved should not greatly exceed $25 \mathrm{mg}$, if correct results are to be expected. With larger amounts of aluminum, positive errors become noticeable regardless of whether the precipitate is dried and weighed, or whether it is titrated, after solution in hydrochloric acid, with potassium bromate. There appears to be a positive error in the determination of aluminum, resulting from probable retention of the reagent by the precipitate, ${ }^{9}$ which is reflected more strongly in the volumetric procedure than in the gravimetric. This supposition was verified by the following experiments.

In two experiments, solutions containing $0.1890 \mathrm{~g}$ of aluminum oxide $(0.1000 \mathrm{~g}$ of $\mathrm{Al})$ were precipitated by the recommended procedure $\mathrm{A}$ and the aluminum oxyquinolate was decomposed in a platinum dish with sulphuric, nitric, and perchloric acids. Following the removal of platinum by precipitation with hydrogen sulphide, the aluminum was precipitated with ammonium hydroxide, filtered, washed, and ignited. The aluminum oxide obtained, corrected for silica and blanks, weighed 0.1890 and $0.1891 \mathrm{~g}$.

TABLE 1.-Results obtained in the determination of aluminum

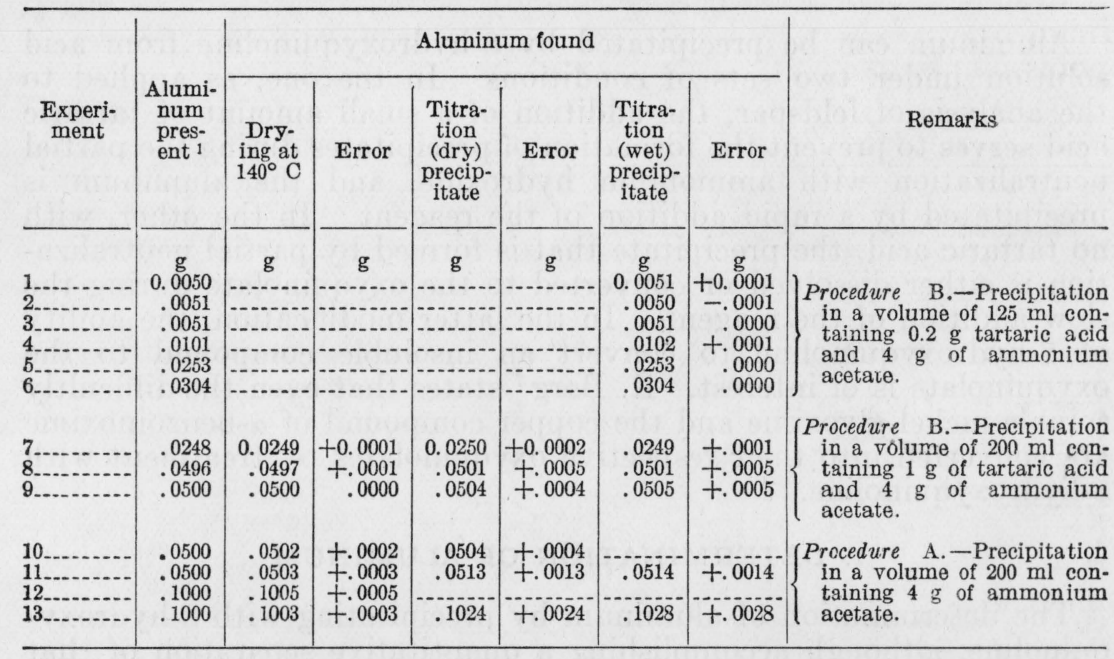

1 Solution prepared by dissolving metallic aluminum ( $99.97_{5}$ percent of $\mathrm{Al}$ ) in hydrochloric acid and standardized by precipitating with ammonium hydroxide and igniting to oxide, with final correction for silica.

With amounts of aluminum exceeding $50 \mathrm{mg}$, the following procedure is recommended. Dissolve the oxyquinolate in an excess of dilute sulphuric acid, evaporate to fumes of that acid and while fuming add successive small portions, 1 to $2 \mathrm{ml}$, of nitric acid (sp gr 1.50) to destroy the bulk of the organic matter. Cool the solution slightly, add one-third of its volume of perchloric acid (60 to 70 percent), and continue heating until the solution is colorless. Cool,

? F. L. Hahn, Z. anal. Chem. 86, 154 (1931). 
dilute with water and heat to dissolve the anhydrous aluminum sulphate. Precipitate the aluminum with ammonium hydroxide, filter, wash, and ignite to oxide in the customary manner. Results must be corrected by blank determinations obtained by carrying similar known amounts of pure aluminum through all steps of the process involved in the destruction of organic matter, and for silica if the operations have been conducted in glass apparatus.

\section{DETERMINATION OF ALUMINUM OXIDE IN FELDSPAR}

The determination of aluminum oxide in feldspar, after removal of silica, presents a case which involves the separation of aluminum from the alkalies, and probably small amounts of calcium, barium, and magnesium. Iron, titanium, zirconium, and other elements are, in general, present in such small quantities as to make their prior removal unnecessary in ordinary work. Under such circumstances rapid routine determinations of alumina can be made by precipitating the aluminum from solutions representing $0.1 \mathrm{~g}$ of feldspar. Such solutions may be obtained from samples in which silica has been determined, or from individual portions of the feldspar which have been decomposed by hydrofluoric and sulphuric acids. In the latter case, it is essential that all hydrofluoric acid be expelled from the solution before attempting the precipitation of aluminum.

Results obtained in the analysis of feldspar by titrating the aluminum oxyquinolate, after solution in hydrochloric acid, with $0.1 \mathrm{~N}$ potassium bromate are given in table 2 .

TABLE 2.-Determination of aluminum oxide in feldspar

\begin{tabular}{|c|c|c|c|c|}
\hline \multirow{2}{*}{ Experiment } & \multicolumn{3}{|c|}{$\mathrm{Al}_{2} \mathrm{O}_{3}$} & \multirow{2}{*}{ Sample } \\
\hline & Present 1 & Found & Difference & \\
\hline 40 & \begin{tabular}{r|} 
Percent \\
18.03 \\
18.03 \\
18.03 \\
19.06 \\
19.06 \\
19.06
\end{tabular} & $\begin{array}{r}\text { Percent } \\
18.01 \\
18.06 \\
18.02 \\
19.10 \\
19.11 \\
19.14\end{array}$ & $\begin{array}{r}\text { Percent } \\
-0.02 \\
+.03 \\
+.01 \\
+.04 \\
+.05 \\
+.08\end{array}$ & $\begin{array}{l}\text { National Bureau of Standards Standard Sample } 70 . \\
\text { Do. } \\
\text { Do. } \\
\text { Do. } \\
\text { Do. } \\
\text { Do. }\end{array}$ \\
\hline 9 & $\begin{array}{l}15.33 \\
15.33 \\
18.75 \\
18.75\end{array}$ & $\begin{array}{l}15.34 \\
15.33 \\
18.75 \\
18.72\end{array}$ & $\begin{array}{r}+.01 \\
.00 \\
.00 \\
-.03\end{array}$ & 73 \\
\hline 11 & $\begin{array}{l}1430 \\
14.30 \\
21.25 \\
21.25 \\
21.25\end{array}$ & $\begin{array}{l}14.40 \\
14.37 \\
21.09 \\
21.15 \\
21.12\end{array}$ & $\begin{array}{l}+.10 \\
+.07 \\
-.16 \\
-.10 \\
-.13\end{array}$ & \\
\hline
\end{tabular}

1 Results given for experiments 7 to 15 are values reported by the analyst for a producer of commercial feldspar who used the standard method (double dehydration for silica and double precipitation with ammonium hydroxide), and who estimates that the values are accurate to \pm 0.2 percent. The results for experiments 13 to 15 may be high because of the presence of an appreciable amount of barium in the sample.

\section{SEPARATION AND DETERMINATION OF BERYLLIUM AND ALUMINUM}

The precipitation of aluminum from acid solution by 8-hydroxyquinoline is of special importance because of the separation from beryllium that it accomplishes. Aluminum and beryllium are frequently associated with elements that either interfere in the deter- 
mination of aluminum, or in the determination of beryllium when the latter is precipitated by ammonium hydroxide in the presence of 8 hydroxyquinoline. When such elements are present preliminary separations effecting their removal are necessary before attempting a precipitation of the aluminum. For this purpose, precipitation with hydrogen sulphide is required if elements such as copper, lead, bismuth, or other elements that form acid-insoluble sulphides are present. The removal of elements such as manganese, magnesium, the alkaline earth metals, and moderate amounts of nickel, cobalt, and zinc, is accomplished by precipitating with ammonium hydroxide, whereas precipitating with an excess of sodium hydroxide serves to separate aluminum and beryllium from iron, titanium, zirconium, and other elements whose hydroxides are insoluble in an excess of alkali.

\section{(a) DETERMINATION OF ALUMINUM IN THE PRESENCE OF BERYLLIUM}

Results obtained by precipitating aluminum oxyquinolate in acid solution, in the presence of beryllium, by procedure $\mathrm{A}$, and drying the precipitate at $140^{\circ} \mathrm{C}$ are given in table 3 . Although satisfactory separations are effected, the results are high because of retention of the reagent by the precipitate. The dried precipitates were dissolved by treatment with suphuric, nitric, and perchloric acids, and examined for beryllium by treating with sodium hydroxide and quinalizarin as recommended by $\mathrm{H}$. Fischer. ${ }^{10}$

TABLE 3.-Determination of aluminum in the presence of beryllium

\begin{tabular}{|c|c|c|c|c|c|}
\hline Experiment & $\underset{\text { taken }^{1}}{\text { Aluminum }}$ & $\underset{\text { taken }}{\text { Beryllium }}$ & Aluminum & Error & $\begin{array}{l}\text { Beryllium } \\
\text { contained } \\
\text { in alumi- } \\
\text { num pre- } \\
\text { cipitate }\end{array}$ \\
\hline 1 & $\begin{array}{l}\mathrm{g} \\
0.1000 \\
.1000 \\
.0500 \\
.0100\end{array}$ & $\begin{array}{l}\mathrm{g} \\
0.1083 \\
.0011 \\
.1083 \\
.1083\end{array}$ & $\begin{array}{l}\mathrm{g} \\
0.1006 \\
.1004 \\
.0503 \\
.0101\end{array}$ & $\begin{aligned} & \mathrm{g} \\
&+ 0.0006 \\
&++0004 \\
&+.0003 \\
&+.0001\end{aligned}$ & mg $\begin{array}{r}0.1 \\
.0 \\
.1 \\
.0\end{array}$ \\
\hline
\end{tabular}

1 See footnote to table 1.

\section{(b) DETERMINATION OF BERYLLIUM IN THE PRESENCE OF ALUMINUM, IRON,}

Results obtained in the determination of beryllium, after its separation from aluminum, iron, titanium, and zirconium by precipitating the latter in acid solution with 8-hydroxyquinoline by the recommended procedure, are given in table 4 . In these experiments, double precipitations with 8-hydroxyquinoline were made to recover the small amount of beryllium retained by the first precipitate, and the combined filtrates were evaporated and treated with sulphuric, nitric, and perchloric acids to destroy the excess reagent before precipitating the beryllium as the hydroxide. Subsequent experiments showed that it is not necessary to remove the excess of 8-hydroxyquinoline from solution, since it does not interfere with the complete precipitation of beryllium by ammonium hydroxide if the solution is allowed to cool before it is filtered.

${ }^{10} \mathrm{Z}$. anal. Chem, 73, 54 (1928). 
TABLE 4.-Results obtained in the determination of beryllium after its separation from aluminum, iron, titanium, and zirconium

\begin{tabular}{|c|c|c|c|c|c|c|}
\hline \multirow{2}{*}{ Experiment } & \multirow{2}{*}{$\underset{\text { taken }}{\mathrm{BeO}}$} & \multicolumn{3}{|c|}{$\mathrm{BeO}$ found } & \multirow{2}{*}{ Error } & \multirow{2}{*}{$\begin{array}{l}\text { Other } \\
\text { elements } \\
\text { present }\end{array}$} \\
\hline & & $\begin{array}{c}\text { First } \\
\text { separation }\end{array}$ & $\begin{array}{c}\text { Second } \\
\text { separation }\end{array}$ & Total & & \\
\hline 1 & $\begin{array}{l}\mathrm{g} \\
0.3004 \\
.1502 \\
.0150 \\
.0015\end{array}$ & $\begin{array}{l}\mathrm{g} \\
0.2996 \\
.1497 \\
.0150 \\
.0014\end{array}$ & $\begin{array}{l}\mathrm{g} \\
0.0006 \\
.0005 \\
.0002 \\
.0000\end{array}$ & $\begin{array}{l}\mathrm{g} \\
0.3002 \\
.1502 \\
.0152 \\
.0014\end{array}$ & $\begin{array}{r}g \\
-0.0002 \\
+.0000 \\
+.0002 \\
-.0001\end{array}$ & $\left\{\begin{array}{l}\mathrm{g} \\
0.10 \mathrm{Al}_{2} \mathrm{O}_{3} \\
.01 \mathrm{Fe}_{2} \mathrm{O}_{3} \\
.005 \mathrm{TiO}_{2} \\
.005 \mathrm{ZrO}_{2}\end{array}\right.$ \\
\hline
\end{tabular}

1 Solution prepared from beryllium carbonate, free from aluminum, and treated to remove elements whose sulphides are insoluble in acid. The solution, after 3 precipitations with ammonium hydroxide to insure removal of any magnesium, was standardized by precipitating with ammoniun hydroxide and igniting to oxide, with final correction for silica.

Incomplete precipitation was observed in a few cases in the separation of beryllium as the hydroxide by precipitating with ammonium hydroxide from hot solutions. To recover any beryllium that may have escaped precipitation the filtrates were allowed to cool, treated with a few drops of ammonium hydroxide and allowed to stand for 24 hours-a precaution also recommended by M. Frommes. ${ }^{11}$

The total beryllium oxide recovered in each experiment was examined for contaminating elements and found to contain less than $0.1 \mathrm{mg}$ of aluminum oxide, a trace of ferric oxide, and no titanium or zirconium oxides. Solutions of the final oxyquinolate precipitate, after treatment with sulphuric, nitric, and perchloric acids to destroy organic matter, were precipitated with an excess of sodium hydroxide, and filtered. The filtrate, when treated with quinalizarin, showed the oxyquinolate precipitate to be free from beryllium.

\section{DETERMINATION OF ALUMINUM IN THE PRESENCE OF MAGNESIUM}

The results given in table 5 were obtained by precipitating aluminum in the presence of magnesium, by the recommended procedures, and drying the aluminum oxyquinolate at $140^{\circ} \mathrm{C}$. The values obtained illustrate again the tendency of the method to yield results that are too high because of retention of the reagent by the precipitate.

TABLE 5.-Determination of aluminum in the presence of magnesium

\begin{tabular}{|c|c|c|c|c|c|}
\hline Experiment & $\underset{\text { taken } 1}{\text { Aluminum }}$ & $\begin{array}{c}\text { Magnesium } \\
\text { taken }\end{array}$ & $\underset{\text { found }}{\text { Aluminum }}$ & Error & $\begin{array}{l}\text { Precipitation } \\
\text { by proce- } \\
\text { dure- }\end{array}$ \\
\hline${ }^{1}{ }^{1}{ }^{2}{ }^{2}{ }^{2}$ & $\begin{array}{r}\mathrm{g} \\
0.0010 \\
.1000 \\
.1000 \\
.1000 \\
.1000 \\
.1000 \\
.1000\end{array}$ & $\begin{array}{l}\mathrm{g} \\
0.1000 \\
.0500 \\
.0500 \\
.1000 \\
.1000 \\
.1000 \\
.1000\end{array}$ & $\begin{array}{r}\mathrm{g} \\
0.0010 \\
.1002 \\
.1005 \\
.1002 \\
.1005 \\
.1006 \\
.1005\end{array}$ & $\begin{array}{r}g \\
+0.0000 \\
+.0002 \\
+.0005 \\
+.0002 \\
+.0005 \\
+.0006 \\
+.0005\end{array}$ & $\begin{array}{l}\mathbf{B} \\
\mathbf{A} \\
\mathbf{A} \\
\mathbf{A} \\
\mathbf{A} \\
\mathbf{B} \\
\mathbf{A}\end{array}$ \\
\hline
\end{tabular}

1 See footnote to table 1.

11 Z. anal. Chem. 93, 287 (1933). 
The aluminum oxyquinolate obtained in experiments 1 to 5 was decomposed as described in section III, 1. Determination of aluminum, and the aluminum, in each, twice precipitated with ammonium hydroxide. The combined filtrates, when evaporated to a small volume and treated with diammonium phosphate, failed to disclose the presence of magnesium. Under conditions of the tests $0.2 \mathrm{mg}$ of magnesium would have been detected.

\section{RECOMMENDED PROCEDURES}

\section{PROCEDURE A (FOR USE IN PRESENCE OF BERYLLIUM)}

To the acid solution containing not more than $0.1 \mathrm{~g}$ of aluminum and $10 \mathrm{ml}$ of hydrochloric acid in a volume of $200 \mathrm{ml}$, add $15 \mathrm{ml}$ of a solution prepared by dissolving $30 \mathrm{~g}$ of ammonium acetate in $75 \mathrm{ml}$ of water, and 8 to 10 drops of a 0.04 -percent solution of bromcresol purple. Add diluted ammonium hydroxide $(1+1)^{12}$ until the indicator becomes a distinct purple. While stirring, add slowly from a burette an acetic-acid solution of 8-hydroxyquinoline in 15 to 25 percent excess of the amount necessary to precipitate the aluminum. Stir occasionally as the solution and precipitate are heated to boiling and boil gently for 1 minute. Allow to cool to $60^{\circ} \mathrm{C}$. Filter the precipitate (using moderate suction) through a $35-\mathrm{ml}$ fritted-glass crucible of fine porosity, such as a 1 bG4 Jena-glass filtering crucible. Wash the precipitate with $100 \mathrm{ml}$ of cool water and determine the aluminum by either of the methods given under procedure B.

\section{PROCE DURE B (FOR USE IN ABSENCE OF BERYLLIUM)}

To the acid solution containing not more than $0.1 \mathrm{~g}$ of aluminum and $10 \mathrm{ml}$ of hydrochloric acid in a volume of $200 \mathrm{ml}$, add tartaric acid in an amount equal to 5 times the weight of aluminum that is to be precipitated. Add $15 \mathrm{ml}$ of a solution prepared by dissolving $30 \mathrm{~g}$ of ammonium acetate in $75 \mathrm{ml}$ of water, and 8 to 10 drops of bromcresol purple solution. Partially neutralize the solution by adding diluted ammonium hydroxide $(1+1)$ until a distinct purple color appears. While stirring, add rapidly an acetic-acid solution of 8hydroxyquinoline in 15 to 25 percent excess of the amount necessary to precipitate the aluminum. Complete the separation by heating, filtering, and washing the precipitate as directed in procedure A.

The treatment of the precipitate to determine the aluminum may be carried out either gravimetrically or volumetrically. In gravimetric determinations, involving as much as $0.1 \mathrm{~g}$ of aluminum, dry the precipitate 3 hours at $135^{\circ} \mathrm{C}$ and weigh as $\mathrm{Al}\left(\mathrm{C}_{9} \mathrm{H}_{6} \mathrm{ON}\right)_{3}$, which contains 5.87 percent of aluminum or 11.10 percent of aluminum oxide.

If aluminum is to be determined by the volumetric procedure, place the crucible and its contents in a $600-\mathrm{ml}$ beaker, add $200 \mathrm{ml}$ of diluted hydrochloric acid $(1+4)$ and heat gently until the precipitate has dissolved. Remove the crucible and rinse the adhering solution back into the beaker. Recover the solution retained in the glass frit by replacing the crucible on the filtration apparatus and washing it with warm dilute hydrochloric acid $(1+9)$. Dilute the acid solution to $400 \mathrm{ml}$ and cool to room temperature $\left(20^{\circ} \mathrm{C} \pm 3^{\circ}\right)$.

\footnotetext{
12 Made by diluting 1 volume of ammonium hydroxide ( $\mathrm{sp}$ gr 0.90 ) with 1 volume of water. When no dilution is specified the use of the concentrated reagent is intended.
} 
Add a solution of standard potassium bromate-potassium bromide ${ }^{13}$ in moderate excess (about 2 to $3 \mathrm{ml}$ ), as determined by test, ${ }^{14}$ or by calculation if the approximate amount of aluminum is known. Stir and let stand for 30 to 60 seconds to insure complete bromination. Add $15 \mathrm{ml}$ of a 20 -percent solution of potassium iodide, stir thoroughly to make sure that the reaction between the bromine and the iodide is complete, and then titrate with a $0.1 \mathrm{~N}$ solution of sodium thiosulphate until the color of the solution becomes a faint brownish yellow. ${ }^{15}$ Add $4 \mathrm{ml}$ of starch solution and titrate until the blue color disappears.

Subtract from the volume of the potassium bromate-bromide added the volume of potassium bromate-bromide solution which is equivalent to the volume of sodium-thiosulphate solution that is required. Multiply the difference, representing the volume of potassium bromate-bromide consumed in reacting with the 8-hydroxyquinoline, by the titer of this solution to obtain the amount of aluminum.

The solutions that are required for the determination of aluminum are as follows:

Potassium bromate-bromide solution $(1.0 \mathrm{~N}) .{ }^{16}$-Dissolve $27.835 \mathrm{~g}$ of potassium bromate and $100 \mathrm{~g}$ of potassium bromide in $600 \mathrm{ml}$ of water and dilute to exactly 1 liter. The potassium bromate-bromide solution is conveniently standardized by determining the ratio between it and a solution of sodium thiosulphate which has been standardized against an iodine solution. This ratio is obtained as follows: To $200 \mathrm{ml}$ of cool water containing $4 \mathrm{~g}$ of potassium iodide, add $4 \mathrm{ml}$ of $N$ bromate (or $8 \mathrm{ml}$ of $0.5 \mathrm{~N}, 16 \mathrm{ml}$ of $0.25 \mathrm{~N}$, or $40 \mathrm{ml}$ of $0.1 \mathrm{~N}$, if such solutions are preferred). Add quickly, while stirring, $40 \mathrm{ml}$ of diluted hydrochloric acid $(1+1)$ and titrate with thiosulphate until the solution is nearly colorless. Add $4 \mathrm{ml}$ of starch solution and continue the titration until the blue color disappears.

In treating oxyquinolates with potassium bromate, 4 gram-atoms of bromine are required for each quinolate radical. Consequently, 12 gram-atoms of bromine represent 1 gram-atom of aluminum, and 1 $\mathrm{ml}$ of an exactly normal solution of potassium bromate-bromide should equal

$$
\frac{26.97}{12} \times \frac{1}{1000}=0.0022475 \mathrm{~g} \text { of aluminum. }
$$

The titer of the bromate solution is then obtained as follows:

Normality factor of
the thiosulphate $\times \frac{\mathrm{ml} \text { of thiosulphate solution }}{\mathrm{ml} \text { of bromate solution }}=\begin{aligned} & \text { normality factor of } \\ & \text { solution }\end{aligned}$

\footnotetext{
13 The bromate solution used in the titration should be of such strength that a reasonable volume is con. sumed in performing the titration. Suitable strengths vary from $0.1 \mathrm{~N}$, for amounts of aluminum up to $10 \mathrm{mg}$, to $N$ for amounts such as 50 to $100 \mathrm{mg}$.

${ }_{14}$ Add 1 drop of the solution to a mixture of 1 drop of potassium-iodide solution and 1 drop of starch solution on a spot plate. If the mixture turns blue, stir the solution containing the aluminum 1 minute and repeat the test. If the blue color does not again appear, more bromate solution must be added and the test repeated. Berg (Z. anal. Chem. $\boldsymbol{\eta n}_{1}, 31$ (1927)) recommends the use of a few drops of a 1-percent aqueous solution of indigo carmine, while Hahn and Vieweg (Z. anal. Chem. 71,124 (1927)) use a diazobenzenesulphonic-acid paper instead of iodide and starch.

${ }_{15}$ In titrating the liberated iodine, the addition of the thiosulphate is continued until the solution is a pale brownish yellow. Care in distinguishing between this color and the yellow color due to the brominated 8-hydroxyquinoline is necessary.

16 Solutions of $0.5,0.25$, and $0.1 \mathrm{~N}$ are prepared by dissolving potassium bromate and potassium bromide $\mathrm{n}$ similar proportions.
} 
This normality factor $\times 0.0022475=\mathrm{g}$ of $\mathrm{Al}$ per $\mathrm{ml}$ of the bromate solution.

Sodium-thiosulphate solution $(0.1 \mathrm{~N})$.--Dissolve $25 \mathrm{~g}$ of sodium thiosulphate $\left(\mathrm{Na}_{2} \mathrm{~S}_{2} \mathrm{O}_{3} \cdot 5 \mathrm{H}_{2} \mathrm{O}\right)$ in $200 \mathrm{ml}$ of recently distilled water and dilute to 1 liter. Standardize this solution against a $0.1 \mathrm{~N}$ solution of resublimed iodine which has been standardized against pure arsenious oxide.

8-Hydroxyquinoline solution (2.5 percent).-Treat $12.5 \mathrm{~g}$ of 8-hydroxyquinoline with $25 \mathrm{ml}$ of glacial acetic acid and warm gently to effect solution. Pour the resulting solution into $450 \mathrm{ml}$ of water at $60^{\circ} \mathrm{C}$. Cool, filter if necessary, and dilute to $500 \mathrm{ml}$.

Potassium-iodide solution (20 percent).-Dissolve $25 \mathrm{~g}$ of potassium iodide in $100 \mathrm{ml}$ of water.

Starch solution.-Dissolve $5 \mathrm{~g}$ of soluble starch and $2.5 \mathrm{~g}$ of salicylic acid in 1 liter of water.

Bromcresal-purple solution $(0.04$ percent).-Triturate $0.1 \mathrm{~g}$ of the dry indicator with $18.5 \mathrm{ml}$ of $0.01 N$ sodium hydroxide and dilute the resulting solution with water to $250 \mathrm{ml}$.

Washington, May 3, 1935. 